REVIEW ARTICLE

\title{
Medical Education: Historical Backward, Current Trends and Challenges
}

\author{
Mohey A. E. Hulail, Eman M. A. Abdelghany* and Ibrahim Hassan Ibrahim \\ Anatomy and Embryology Department, Faculty of Medicine, Zagazig University, Egypt
}

\begin{abstract}
*Corresponding Author:
Eman M. A. Abdelghany

Anatomy and Embryology

Department, Faculty of

Medicine, Zagazig University,

Egypt

eman_pubmed@yahoo.com
\end{abstract}

$\begin{array}{ll}\text { Submit Date } & 2018-11-11 \\ \text { Revise Date } & 2018-12-13 \\ \text { Accept Date } & 2018-12-14\end{array}$

\begin{abstract}
The evolution of medical education started since ancient times. It depended on a master-student relationship. The master was a perfect expert concerned with learning and interested to his trainers and followers. In the early 1900s Abraham Flexner, an American higher education expert, suggested that medical schools must be linked to universities, should have a based curriculum and strong educational programs including fluently basic medical sciences and all stages of medical education should be given in classes, laboratories and hospitals. WHO recommended integration of topics in medical education to overcome the redundancy of knowledge and to enhance student ability on problem-solving, clinical skills, and critical thinking and deal more with preventive medicine and health of the society. Problem-based learning (PBL) is a common method in medical schools around the world. Many educators suggested that a PBL curriculum had to be strengthened by a limited number of well-chosen lectures. Unfortunately traditional lectures are still the most popular instructional method in the universities. Educational innovation and reform new methods of integrated teaching challenged teachers to change how they plan curriculum and make clinical teaching relevant to the lessons taught using these newer methods. The balance of clinical and basic medical sciences and their integration in a manner that best serves the medical student are sure to be the focus of expected innovations in medical education.
\end{abstract}

Keywords: Problem-based learning, integrated curricula, education.

\section{INTRODUCTION}

M edical education aimed to teach medical knowledge and clinical skills to medical students as well as to provide the society with professional practitioners ${ }^{[1]}$. Its history is bonded to the history of medicine itself since ancient times. Learning of practical skills and transmission of knowledge at ancient times depends on the masterstudent relationship. Medical knowledge expansion and incorporation of new technologies in medical practice brought drastic changes in medicine and, therefore, in medical education. The history of medical education can be roughly divided into three stages. First stage, extended from the ancient times until 1910 (called Pre-Flexner stage) was based on master-trainer model. The second stage, extended from 1910 up to 1970 (called Flexner stage), at which medical education depended on the biomedical model.
The third stage, (called Post-Flexner stage), is a student-centered medical education ${ }^{[2]}$.

\section{Pre-Flexner stage}

Evolution of medical education begun in the ancient Egyptian and Hindu civilizations who were the first to record systematized practical knowledge on diseases and their treatment ${ }^{[3]}$. At these stages learning and transmission of practical skills depended on a master who was a perfect expert concerned with learning and interested to his trainers and followers. Those who were interested to learn the medical skills searched for the known masters, following any of them in his daily practice to learn medicine in a direct personal contact ${ }^{[4]}$. The master-student relationship was flourished in the Hindu, Arabic, Greek and Roman civilizations.

Egyptians were considered the best doctors in the ancient world starting from before 2600 B.C. until the fourth century B.C. They wrote 
medical texts on papyrus and sold these papyri by the Egyptian temples to physicians. Egyptian papyri discovered indicated advanced surgical and pharmacological practice [5]. Kahun Gynecology Papyrus dating back to 2000 B.C. included descriptive methods for diagnosis of pregnancy and fetal sex detection. Edwin Smith Papyrus and Ebers papyrus (about1600 BC) are the most famous medical papyri. These papyri described the anatomy of the heart, blood circulation, pulse, head, brain, and methods of physical examinations [6].

Charaka; Hindu physician like Hippocrates 500 B.C., was a perfect teacher and a good writer [4]. Charaka advised students who want to study medicine to seek for a good master having approved practical skills and confident with his treatment, kind to his students and patients and to follow him in his daily activities [7].

Hippocrates, A Greek physician, (460 B.C370 B.C.), is the most famous physician in the entire history. $\mathrm{He}$ is called the father of modern medicine. He stated that treatment and prognosis of the disease should depend on scientific observations and on the structure of human body thus he separated Greek medicine from superstitions, magic and religion. He was the first physician to believe that thoughts, ideas and feelings come from the brain and not from the heart, contrary to the belief of many others [8].

During the Roman period (129-200 AD) a famous Greek physician (named Galen) emerged. He was a brilliant anatomist and pioneer of experimental physiology [9]. Galen's wrote several textbooks in medicine including the fundamentals of the medical science which are still significant. Galen was the first to attempt to formulate a classification of diseases and symptoms with a strong basis in anatomy. Textbooks of Galen and Hippocrates were the most valuable manuals for practitioners throughout fourteen centuries [10].

Muslim physicians had significant contribution in the field of medical education. Ibn-Sina (Avicenna) (980-1037) is one of the greatest medical teachers in history of medicine. He wrote many textbooks as Canon of Medicine and the Book of Healing, which remained popular textbooks in the Islamic and Medieval Europe for centuries. Ibn Nafis (1210-1288 AD) described human circulation [11].

In the Ninth century a medical school developed in Salerno In Italy [12].It was the most important medical learning center at that time. It systematized topics of medical knowledge, distinguished theory from practice and changed the idea of the masterlearner relationship. The master became represented by a group of masters. The trainers at Salerno created new medical schools once returned back to their original countries and disseminated this way of teaching in France, Spain and England. The graduates of these schools played a major role in discoveries of modern medicine [13].

In nineteenth-century the medical knowledge expanded and a challenge existed in how to incorporate this knowledge in medical education. Medical schools in Europe were mandatory linked to universities. These universities made major changes in their curricula by introducing the basic medical knowledge through lectures and laboratory practices, incorporating teaching staff in the educational methodology, learn students practical skills on patients under supervision of physicians of renowned clinical skills in selected hospitals [14].

Sir William Osler (1849 -1919) a Canadian physician, had a distinctive role in medical education and medical practice $[15,16]$. Osler contribution to the advancement of medical education greatly enhanced clinical teaching. $\mathrm{He}$ was also one of the fathers of Internal Medicine and one of the first who formalized it as a discipline. He introduced the practice of bedside teaching stating that the student must begin with the patient, continues with the patient and ends his studies with the patient. The student must be taught how to observe, given basic knowledge in the form of lessons and lectures and use books and classes as tools [17].

Osler as an internal medicine chief participated by a model of pre-medical scientific program taught by full-time researchers followed by clinical training one taught by professors of the highest clinical skill in the hospitals of the Johns Hopkins 
University School of Medicine in Baltimore in 1893 [18].

\section{Flexner period}

In the early 1900s, the American Medical Association (AMA) and the Association of American Medical Colleges (AAMC) were worried about the state of medical education in United States and Canada and decided that it ought to be reevaluated. They asked the Carnegie Foundation to revise the state of medical education in the United States. The Carnegie Foundation chose Abraham Flexner to be a leader for the group undertaking this study [19].

Flexner released his report regarding medical education in the United States and Canada in 1910. The report advised that medical schools must be linked to universities. They should have a university based curriculum and strong educational programs including fluently basic medical sciences. He described a disciplinebased curriculum composed of 2 years of basic medical sciences with laboratory experience followed by 2 years of clinical training. He recommended that all stages of medical education should be given in classes, laboratories and hospitals. The medical schools should have high quality standards and strive for better learning environments, facilities, clinical training to gain specific goals and objectives. He recommended that the medical schools should use standards for admission of students. Flexner claimed that the master-apprentice model failed to train qualified physicians and there was a great necessity for science knowledge in medical education [20].

Flexner recommended that teaching the basic medical sciences must be associated with active involvement of the student in the learning process. The student doesn't only just watch, listen, memorize but also he must do. The curriculum should have redundancies to compensate the deficiencies in one subject by supplementation from the other. Multiple methodologies as bedside teaching, case study, laboratory and clinical skills had to be used. Students should be trained to summarize and systematize the learned subject [21].

The changes built upon Flexner report had great remarkable effects on medical education over the following years and decades. It led to a standard system that used and remained intact and unchanged in most American medical schools throughout the 20th century. Moreover it strongly influenced curriculum design around the world for many decades following the report. Medical schools implemented a curriculum of pre-clinical (basic science) phase and clinical science phase.

However the curriculum proposed by Flexner did not promote cross-talk between medical disciplines with a lack of integration. Each department became responsible for delivery of highly discipline-specific basic science knowledge to medical students in the preclinical years. Thus, much of basic science teaching focused on in-depth scientific facts rather than on the relevance of the discipline to medical practice. Medical educators noticed that students had a poor grasp and recall of the basic knowledge. Therefore the students had inability to apply concepts and principles acquired in the preclinical years to medical problems encountered in the clinics [22]. The lack of clinical relevance, lack of integration, and the division of pre-clinical and clinical instruction caused dissonance and dissatisfaction among clinical teachers and students alike [23].

A review by the Oxford Centre for Staff Development identified five aspects of educational programs that are associated with students adopting undesirable shallow learning techniques and failing to grasp the underlying principles of the topic [24]. The five features are heavy workload; excessive amount of course material; little opportunity to pursue subjects in depth; little choice over topics or methods of study; and an anxiety provoking assessment system that rewards or tolerates regurgitation of factual information [25].

\section{Post-flexner period \\ Disadvantages of traditional medical education}

With entering the last quarter of the 20th century there was an explosion of knowledge in the biomedical sciences. Medical education had growing problems due to the consequent increased demands on curricular time [26]. It is impossible to cover all the available knowledge which had become broad and 
diverse and become so vital to define which of these were essential [27].

The students had to learn many subjects at the same time. They are loaded with an unbalanced and disproportionate knowledge. They had no chances to acquire skills as critical thinking, problem solving, and decision making or the ability to investigate, diagnose, and treat the patient as a whole [28]. Medical education is designed as a teacher-centered method as lecturers tend to highlight knowledge, content without attention to student flexibility, gaining problem solving, critical thinking and independent learning $[29,30]$.

Students had to passively absorb information in silent isolation and then expected to recall the knowledge in a competitive manner during examinations. Several areas of redundancy, repetition and overlapping are determined. The students will not learn the relevance of basic and biomedical sciences to clinical practice. A wide gap existed between the qualitative and quantitative advancement in medical education [31].

The vast and growing medical knowledge obliged the educators to be more selective to assess the acquired knowledge, and to pick the reliable and thorough sources upon which they can construct the educational knowledge. This looks like as searching for a needle in a haystack [32].

At the start of a medical career, the knowledge that a practitioner remembered might not be the right one required to solve future problems [33].

Densen [34] reported that in 1950 the medical knowledge is doubled along 50 years. In 2010 it is estimated to be doubled along 3.5 years, and in 2020, it is expected to take 73 days only to be doubled. This huge growth of medical knowledge is one of the most important challenges confronting medical institutions in designing their curricula [35, 34].

Shojania et al. [36] showed that information gained through clinical research is relevant for approximately 5.5 years before relevant clinically change occurs. Absorbing and incorporating information that changes at such an amazing rate presents a real challenge.
The knowledge in the current trends of undergraduate medical education is gained in isolation. Each subject in basic sciences is taught in separate blocks without correlation of the knowledge with related subjects. Therefore the students cannot grasp the subject as a whole. There was a wide gap between the course content and clinical practice [37]. These obliged medical schools to reform their curricula towards more integrated models [38]. The role of the basic medical sciences in the 21 st century must be thoroughly reevaluated [39].

\section{Calls for change}

World Health Organization [40], the American Association of Medical Colleges [41] and Council of World Federation for Medical Education [42] recommended the urgent need of profound changes in the learning methods to concern on understanding principles rather than memorizing facts. The undergraduate medical curriculum must be reformed in integrated subjects with enhancement of student ability on problemsolving, clinical skills, and critical thinking and deal more with preventive medicine and health of the society [30]. Integration of subjects facilitates acquisition of knowledge and clinical skills of the students [43].

Many strategies were used to reform medical curricula to confront problems with the traditional curriculum. Oxford Centre for Staff Development suggested a design for curriculum reform termed the SPICES model. According to this model, the curriculum has been transformed from teacher centered to student-centered, doctor-oriented to patient oriented, isolated to integrated, hospital-based to community-based, apprenticeship to elective-driven and from subject-based to system based [44].

The integrated curriculum in undergraduate medical education (UME) is designed on the fact that an active, learner-centered environment enhances critical thinking, deeper understanding of basic science and its relevance to clinical practice [45].

Trends in medical education are shifting from passive to active learning. Self-directed learning has been encouraged for physicians to overcome this inquiry [46-48].

Models of reform 
A curriculum is the framework or design of the learning process during a course of study. It includes the teaching and assessment methods and the learning resources. A syllabus is the knowledge content of the course. It is a part of the curriculum. Integration is breaking down the barriers between disciplines in order to provide better learning opportunities, meaningful knowledge more relevant to clinical practice [49]. Integration is defined as inter-disciplinary, multidisciplinary, trans-disciplinary, intermingled and mixed subjects [50]. Integration of subjects facilitates acquisition of knowledge and skills. It enables the students to co-relate the basic sciences with the clinical practice. It enhances deeper understanding and increase effectiveness of the learning process [51].

The association for Medical Education in Europe; AMEE [52] defined the integration as a fully synchronous, trans-disciplinary knowledge including basic medical sciences and the clinical sciences weaving together through all years of a medical curriculum.

Shoemaker [53] defines integrated curriculum as bringing together various aspects of knowledge regarding a subject into meaningful association.

Several studies were previously done to compare the assessments of students taught in an integrated approach with those taught on the traditional method. These studies revealed that the average marks obtained by students taught in an integrated approach were greater than the marks obtained by students taught on the traditional method [51, 34]. Moreover students trained with integrated curriculum had more accurate clinical skills than those trained in a conventional manner [54]. Integrated teaching improves the critical thinking of students and enhances their interest in topics and abolishes the fear toward the subject. Integration in medical education aims to teach various subjects in a coordinated manner to ensure symphonic functioning of the educational processes [51]. Integrated and organized manner of teaching assists medical students to become competent in different subjects and rightly apply their knowledge and skills for the benefit of the patients and the community.
The medical schools make significant changes in their curriculum from a program consisting of discipline based courses to an integrated curriculum that typically moves through the various systems in the body, i.e. cardiovascular, reproductive, gastrointestinal, etc. The anatomy, physiology, biochemistry, etc., related to each system are presented together $[55,56]$.

\section{How to reform curriculum?}

The curriculum design must fulfill several criteria including what is the suitable type of physician required for the health care system, how curriculum changes can be implemented, choosing the learning objectives and planning how they can be achieved? Finally feedback and assessment of the curriculum had to be done $[57,58]$.

Curriculum reform must consider enhancing self- learning and critical thinking among the students [59.60]. Strategy of learning-to-learn (self- learning) is a major part of modern curricula. It encourages the students to be able to discover as well as to generate knowledge relevant to their needs without guidance and direction from teachers [61].

Assessment methods should be part of the design of the curriculum and courses, in order to achieve the intended objective of integration [62].

\section{Types of integration}

Medical schools across the world use different models of curricula in undergraduate medical education. The varieties of these curricula include traditional discipline-based curriculum, integrated curriculum, organbased curriculum, competency based curriculum, problem-based learning curriculum and community oriented curriculum. Each curriculum has its advantages and disadvantages. Some medical schools have two types of combined curricula as organ-based curriculum and problem-based learning [63].

The traditional discipline-based curriculum is still used in some medical schools across the globe, including India, some other Asian countries, and some Caribbean medical schools. The students are not exposed to clinical education or patients until the third year of their medical program. During the first two years of their medical course, the 
curriculum is composed completely of basic sciences.

Integration in medical education can be classified as horizontal, vertical, and spiral types. Horizontal integration brings the various disciplines, topics together in a restricted time period. For example an integrated course of respiratory system comprised of weaving related topics that previously taught separately in various subjects such as Physiology, Biochemistry and Anatomy. Horizontal integration reduces content redundancy. It includes additional activities as problem based learning to promote self-directed study and critical thinking. Vertical integration brings basic and clinical science together with blurring the boundary between preclinical and clinical years. It engages students early in clinical practice and allowed them in clinical years to revise the underlying basic medical knowledge when required. It transforms the $\mathrm{H}$-shaped curriculum of horizontal integration into Z-shaped curriculum. Organ (system) based curriculum runs according to each organ system with both horizontal and vertical integration. Organ-based curriculum is one of the most popular curricula for undergraduate medical education in American medical schools and followed in very few Caribbean medical schools [64].

Horizontal and vertical integration had an advance over traditional curriculum. However an active process of learning is still lacking. This weakness is dealt in many institutions by the introducing problem based learning (PBL) in small group teaching by careful selection of a clinical problem. These enhance the students early in the curriculum to appreciate the relevance of acquired knowledge to clinical practice, promote the habit of selflearning throughout their careers to learn how to gain the right knowledge they require for problem solving and to construct the parts of knowledge gained from different sources together in a meaningful way [65].

Spiral integration introduces the basic sciences, clinical practices and skills, health promotion, and ethics together throughout the curriculum with enhancing the students to revise the previous knowledge to link it with the current knowledge to achieve higher levels of learning [66]. The spiral curriculum reinforces the learned topic or subject by continuing exposure to it to overcome the common problem in traditional methods as the topics learned by students early in the curriculum are forgotten later [67]. The spiral curriculum permits the students to move from simple knowledge and practice to more complex one so they could achieve better understanding by exploring the same topics at deepening levels. It also breaks the barriers and boundaries between courses and departments [68].

Community-based curriculum is another approach in undergraduate medical education in recent years where a community approach is of primary importance [69]. The students are involved in community services and primary care centers from the beginning and throughout the program. Students are committed to community health or public health and preventive services. This curriculum is still in its initial stages. Some schools have implemented it as a pilot project. Competency-based curriculum is one of the recent designs of the curriculum in medical education [70]. It is a method of training where students are assessed by their progression regarding their ability to perform certain tasks [71]. It became well-established in medical education curricula as it is a reliable method to ensure that every graduate acquired the required skills and knowledge. It is also effective in identifying areas of weakness and strength in learners and helps teachers to assess appropriate learning outcomes [72, 73]. It helps to improve resident performance and patient safety as it moves from knowledge acquisition towards knowledge application [74, 75].

Problem-based learning (PBL) was firstly introduced at McMaster University Medical School in Canada in the late 1960s and it becomes a common component in medical schools around the world [76, 33]. It is student-centered collaborative learning and promotes self-directed learning throughout life career [77]. It helps the students to acquire knowledge of both basic and clinical sciences and practical and clinical skills and encourages deep learning $[78,79]$. 
During the past few decades, many medical schools engaged problem based learning in their curriculum [80].

Many medical schools around the world use PBL only. Four North American schools currently offer only a problem-based curriculum with no traditional curriculum as a supplement or alternate. They are McMaster, Mercer, Harvard, and Hawaii medical schools. Some schools offer a single curriculum that blends both concepts, that is, an integral PBL parallel and reinforce a traditional curriculum. Many educators suggested that a PBL curriculum had to be strengthened by a limited number of wellchosen lectures [81].

In PBL the students are divided into small groups. Each group included five to eight students [82] or 8 to 12 students [83]. The students act together in a group supervised by a faculty member; called facilitator or tutor. They are given a clinical problem without previous readings, or preparation to stimulate them to search for required knowledge [82].

According to [84, 85] PBL is typically carried out in three stages. At the first stage the students define and evaluate the clinical problem and attempt to determine its underlying causes either anatomical, physiological, biochemical, or behavioral dysfunctions. The second stage is selfdirected learning through which the students study outside the tutorial session, using any relevant learning resources. The third stage begins when the students come back to the tutorial session. They apply the newly acquired knowledge to reach a proper solving for the problem. In PBL the students had to explore rather than to receive passive knowledge. The tutors manage and direct the learning process rather than giving information. They had to enhance students' active learning, clinical skills and habits of continued learning [86].

The tutor must ensure that all students are involved in the problem-solving process and must familiarize students with the resources needed as library references and databases to solve the problem $[87,88]$.

However graduates of PBL curriculum tend to choose careers in family medicine $[76,89]$.

\section{Challenges and pitfalls confronting integration}

Many medical institutes still adopt traditional lectures are still the most popular instructional method in the universities [90]. Most of the university teachers are not familiar with modern teaching methods. Most of them have been taught in learning environments that were instructor centered, therefore, they teach in this way too. The sluggish response to change is the characteristic of traditionalism of the educational institutions [91, 92].

Lane [93] suggested that many factors might resist change in medical education. These are strong standing traditions, lack of real need for change, strong disciplinary empathy of faculty members, need of departmental protection of curriculum time, lack of experience, lack of time to implement changes, fear of loss of resources.

\section{CONCLUSION}

The relevance of basic medical sciences has become redefined by their role in supporting clinical practice rather than being, just, a knowledge base of physicians. In the new strategies of medical education there has been a worldwide adoption of integrated curricula, indicating a greater for the concept of updated rather than traditional learning of medical sciences. Changes in curricula content and design should be in alignment with changes in our understanding of the concept of how students learn and clarity around the role of the physician. Medical educators are being challenged to integrate the basic sciences into their clinical practice in all content domains. New methods of integrated teaching using simulation models have enabled better education but challenged teachers to change how they plan curriculum and make clinical teaching relevant to the lessons taught using these newer methods. The balance of clinical and basic medical sciences and their integration in a manner that best serves the medical student are sure to be the focus of expected innovations in medical education.

\section{REFERENCES}

1- Robinson GC. Adventures in medical education. Commonwealth Fund; 1957.

2- Balcioglu H, Bilge U, Unluoglu I. A historical perspective of medical education. Journal of Education in Science, Environment and Health. 2015;7; 1(2):111-4. 
3- da Silva LF, Baracat EC. Medical education-historic perspective and future challenges. Revista de Medicina. 2016;1; 95(1 S1):28-37.

4- Fulton JF. History of medical education. British medical journal. 1953; 29; 2(4834):457.

5- Gabriel RA, Metz KS. A History of Military Medicine: From the Renaissance through modern times. Greenwood Press; 1992.

6- Stevens JM. Gynaecology from ancient Egypt: The papyrus Kahun: A translation of the oldest treatise on gynaecology that has survived from the ancient world. The Medical Journal of Australia. 1975; 2(25-26):949-52.

7- Lakshmi Pathi A. A Textbook of Ayurveda, vol. 1. Bezwada, India. 1944.

8- El-Gammal SY. The role of Galen in the development and progress of medical sciences. Bull Indian Inst Hist Med Hyderabad. 1998; 28:119-27.

9- Freemon FR. Galen's ideas on neurological function. Journal of the History of the Neurosciences. 1994;1; 3(4):263-71.

10-Galen BM. the origins of Experimental Neurosurgery. Austin J Surg. 2014;1(2):1009.

11-Courtemanche A. Abulcasis, Avicenna, and Galen: a forensic investigation by a 14th century Jewish physician. Canadian bulletin of medical history= Bulletin canadien d'histoire de la medecine. 2002; 19(2):441-53.

12-Stelmaschuk A. The School at Salerno: origin of the European Medical University. HISTORY OF MEDICINE DAYS. 2001 23; 65.

13-Kiple KF. The history of disease. The Cambridge history of medicine. 2006:10-45.

14-Abreu M. Os caminhos dos livros. Alb; 2003.

15-Bailey I. Sir William Osler (1849-1919): physician, teacher, historian, biographer, bibliophile. Journal of medical biography. 1993; 1(1):2-10.

16-Stone MJ. The wisdom of Sir William Osler. The American journal of cardiology. 1995; 1; 75(4):269-76.

17-Bryan CS. Fever, famine, and war: William Osler as an infectious diseases specialist. Clinical infectious diseases. 1996 Nov 1; 23(5):1139-49.

18-Harvey AM, Brieger GH, Abrams SL, McKusick VA. A model of its kind: A century of medicine at Johns Hopkins. JAMA. 1989 Jun 2; 261(21):313642.

19-Drake RL. A retrospective and prospective look at medical education in the United States: Trends shaping anatomical sciences education. Journal of anatomy. 2014 Mar; 224(3):256-60.

20-Magzoub ME, Schmidt HG. A taxonomy of community-based medical education. Academic Medicine. 2000 Jul 1; 75(7):699-707.

21-LeeKeenan D, Edwards CP. Using the project approach with toddlers. Faculty Publications, Department of Child, Youth, and Family Studies. 1992 May 1:11.

22-Wilkerson L, Stevens CM, Krasne S. No content without context: integrating basic, clinical, and social sciences in a pre-clerkship curriculum. Medical Teacher. 2009 Jan 1; 31(9):812-21.
23-Pawlina W. Basic sciences in medical education: why? How? When? Where?. Medical teacher. 2009 Jan 1; 31(9):787-9.

24-Lowry S. Strategies for implementing curriculum change. BMJ: British Medical Journal. 1992 Dec 12; 305(6867):1482.

25-Kevelighan EH, Duffy S, Walker FF. Innovations in teaching obstetrics and gynaecology--the Theme Afternoon. Medical education. 1998 Sep; 32(5):517-21.

26-National Research Council. Inquiry and the national science education standards: A guide for teaching and learning. National Academies Press; 2000 May 3.

27-da Silva LF, Baracat EC. Medical education-historic perspective and future challenges. Revista de Medicina. 2016 Jul 1; 95(1 S1):28-37.

28-Medical Council of India. Vision 2015 (online). March 2011.

29-Zhenhui R. Matching teaching styles with learning styles in East Asian contexts. The Internet TESL Journal. 2001 Jul; 7(7):5.

30-Wang V, Farmer L. Adult teaching methods in China and Bloom's taxonomy. International Journal for the Scholarship of Teaching and Learning. 2008; 2(2):13.

31-Harden RM. Ten questions to ask when planning a course or curriculum. Medical education. $1986 \mathrm{Jul}$; 20(4):356-65.

32-Swanwick R, Hendar O, Dammeyer J, Kristoffersen A, Salter J, Simonsen E. Shifting contexts and practices in sign bilingual education in northern Europe. Bilingualism and bilingual deaf education. 2014 Jun 2:218-310.

33-Wood DF. ABC of learning and teaching in medicine: Problem based learning. BMJ: British Medical Journal. 2003 Feb 8; 326(7384):328.

34-Densen P. Challenges and opportunities facing medical education. Transactions of the American Clinical and Climatological Association. 2011; 122:48.

35-Brook RH. Continuing medical education: let the guessing begin. JAMA. 2010 Jan 27; 303(4):35960.

36-Shojania KG, Sampson M, Ansari MT, Ji J, Doucette S, Moher D. How quickly do systematic reviews go out of date? A survival analysis. Annals of internal medicine. 2007 Aug 21; 147(4):224-33.

37-Reynolds J, Skilbeck M. Reynolds, John and Malcolm Skilbeck, Culture and the Classroom. London: Open Books, 1976.

38-Prideaux D. Curriculum design. (ABC of learning and teaching in medicine). British medical journal. 2003 Feb 1; 326(7383):268-71.

39-Cooke M, Irby DM, Sullivan W, Ludmerer KM. American medical education 100 years after the Flexner report. New England journal of medicine. 2006 Sep 28; 355(13):1339-44.

40-World Health Organization. The Declaration of Alma Ata. Presented at. InInternational Conference on Primary Health Care. Alma Ata 1978. 
41-American Association of Medical Colleges. Annual report.1984-1985.1-52.

42-Executive Council. International standards in medical education: assessment and accreditation of medical schools'-educational programmes. A WFME position paper. Medical Education. 1998 Sep; 32(5):549-58.

43-Doraisamy R, Radhakrishnan S. The effectiveness of integrated teaching over traditional teaching among first year MBBS students: A preliminary Study. Medical Journal of Dr. DY Patil University. 2013 Apr 1; 6(2):139.

44-Harden RM, Sowden S, Dunn WR. Educational strategies in curriculum development: the SPICES model. Medical education. 1984 Jul; 18(4):284-97.

45-Kulasegaram KM, Martimianakis MA, Mylopoulos M, Whitehead CR, Woods NN. Cognition before curriculum: rethinking the integration of basic science and clinical learning. Academic Medicine. 2013 Oct $1 ; 88(10): 1578-85$.

46-Meyers C, Jones T. Promoting Active Learning: Strategies for the College Classroom Jossey. 1993.

47-Irby DM, Cooke M, O'brien BC. Calls for reform of medical education by the Carnegie Foundation for the Advancement of Teaching: 1910 and 2010. Academic Medicine. 2010 Feb 1; 85(2):220-7.

48-Murad MH, Coto-Yglesias F, Varkey P, Prokop LJ, Murad AL. The effectiveness of self-directed learning in health professions education: a systematic review. Medical education. 2010 Nov; 44(11):1057-68.

49-Bradley P, Mattick K. Integration of basic and clinical sciences-AMEE 2008. Peninsula College of Medicine and Dentistry, UK. 2008.

50-Czerniak CM, Johnson CC. Interdisciplinary science teaching. Handbook of research on science education. 2007:537-59.

51-Kate MS, Kulkarni UJ, Supe A, Deshmukh YA. Introducing integrated teaching in undergraduate medical curriculum. Int J Pharm Sci Res. 2010; 1(1):18-22.

52-The association for Medical Education in Europe AMEE. Abstract Book. 2014 August/ September; 1-906.

53-Shoemaker BJ. Integrative Education: A Curriculum for the Twenty-First Century. OSSC Bulletin. 1989 Oct; 33(2):n2.

54-Schmidt H, Machiels-Bongaerts M, Hermans H, Ten Cate O, Venekamp R, Boshuizen H. The development of diagnostic competence: A comparison between a problem-based, an integrated, and a conventional medical curriculum. Academic Medicine. 1996 Jan 1; 71:658-64.

55-Drake RL. A unique, innovative, and clinically oriented approach to anatomy education. Academic Medicine. 2007 May 1; 82(5):475-8.

56-Fishleder AJ, Henson LC, Hull AL. Cleveland Clinic Lerner College of Medicine: an innovative approach to medical education and the training of physician investigators. Academic Medicine. 2007 Apr 1;82(4):390-6.
57-Kern DE, Bass EB, Thomas PA, Howard DM. Curriculum development for medical education: a six step approach. JHU Press; 1998.

58-Steinhaeuser J, Chenot JF, Roos M, Ledig T, Joos S. Competence-based curriculum development for general practice in Germany: a stepwise peer-based approach instead of reinventing the wheel. BMC research notes. 2013 Dec; 6(1):314.

59-McNeill P. Inquisitive Learning in the Medical Curriculum. UNSW Faculty of Medicine. Key Issues Meeting, September1999.

60-Hilliard J. Communication skills are vital in all we do as educators and clinicians. Education for health. 2000 Jul 1;13(2):157.

61-Iedema R, Degeling P, Braithwaite J, Kam Yin Chan D. Medical education and curriculum reform: putting reform proposals in context. Medical Education Online. 2004 Dec 1;9(1):4368.

62-De Campos LC, Dirani EA, Manrique AL. Project approaches to learning in engineering education: The practice of teamwork. Springer Science \& Business Media; 2012 Sep 15.

63-Arja S. Undergraduate Medical Education and Curricula. Immunother Res. 2017;1(1):3.

64-Brauer DG, Ferguson KJ. The integrated curriculum in medical education: AMEE Guide No. 96. Medical teacher. 2015 Apr 3;37(4):312-22.

65-Vidic B, Weitlauf HM. Horizontal and vertical integration of academic disciplines in the medical school curriculum. Clinical Anatomy: The Official Journal of the American Association of Clinical Anatomists and the British Association of Clinical Anatomists. 2002 May;15(3):233-5.

66-Dangprapai Y. Integration in Medical Education: A Brief Introduction for Physiology Educators. J Physiol. 2016; 29(2):25-9.

67-Kabara JJ. Spiral curriculum, Journal of Medical Education. 1972; 47, pp. 314-316.

68-Doctors GT. Recommendations on Undergraduate Medical Curriculum. London: General Medical Council. 1993.

69-Hamad B. Community-oriented medical education: what is it?. Medical education. 1991 Jan; 25(1):1622.

70-Kerdijk W, Snoek JW, van Hell EA, CohenSchotanus J. The effect of implementing undergraduate competency-based medical education on students' knowledge acquisition, clinical performance and perceived preparedness for practice: a comparative study. BMC medical education. 2013 Dec; 13(1):76.

71-Brightwell A, Grant J. Competency-based training: who benefits? Postgraduate medical journal. 2013 Feb 1; 89(1048):107-10.

72-Iobst WF, Sherbino J, Cate OT, Richardson DL, Dath D, Swing SR et al. International CBME Collaborators. Competency-based medical education in postgraduate medical education. Medical teacher. 2010 Aug 1; 32(8):651-6.

73-Iglar K, Whitehead C, Takahashi SG. Competencybased education in family medicine. Medical teacher. 2013 Feb 1; 35(2):115-9. 
74-Carraccio C, Wolfsthal SD, Englander R, Ferentz $\mathrm{K}$, Martin C. Shifting paradigms: from Flexner to competencies. Academic medicine. 2002 May 1; 77(5):361-7.

75-Leung WC, Diwakar V. Learning in practiceCompetency based medical training: review Commentary: The baby is thrown out with the bathwater. Bmj. 2002 Sep 28; 325(7366):693-6.

76-Neufeld VR, Woodward CA, MacLEOD SM. The McMaster MD program: a case study of renewal in medical education. Academic medicine: journal of the Association of American Medical Colleges. 1989 Aug; 64(8):423-32.

77-Charlin Karen Mann Penny BE. The many faces of problem-based learning: A framework for understanding and comparison. Medical teacher. 1998 Jan 1; 20(4):323-30.

78-Coles CR. Differences between conventional and problem-based curricula in their students' approaches to studying. Medical education. 1985 Jul; 19(4):308-9.

79-Solomon P. Problem-based learning: a direction for physical therapy education?. Physiotherapy Theory and Practice. 1994 Jan 1;10(1):45-52.

80-Leung KK, Lue BH, Lee MB. Development of a teaching style inventory for tutor evaluation in problem-based learning. Medical Education. 2003 May; 37(5):410-6.

81-Donner RS, Bickley H. Problem-based learning in American medical education: an overview. Bulletin of the Medical Library association. $1993 \mathrm{Jul}$; 81(3):294.

82-Mansur DI, Kayastha SR, Makaju R, Dongol M. Problem based learning in medical education. Kathmandu Univ Med J. 2012 Oct;10(4):78-82.

83-Schmidt HG. Problem-based learning: rationale and description. Medical education. 1983 Jan; 17(1):116.

To Cite This Article: Hulail MA, Abdelghany EMA, Ibrahim IH. Medical Education: Historical Backward, Current Trends and Challenges. ZUMJ, 2018;
84-Barrows HS. A taxonomy of problem-based learning methods. Medical education. 1986 Nov;20(6):481-6.

85-Koschmann T, Kelson AC, Feltovich PJ, Barrows HS. Computer-supported problem-based learning: A principled approach to the use of computers in collaborative learning. CSCL: Theory and practice of an emerging paradigm. 1996:83-124.

86-Allen DE, Duch BJ, Groh SE. The power of problem-based learning in teaching introductory science courses. New directions for teaching and learning. 1996 Dec; 1996(68):43-52.

87-Arambula-Greenfield T. Implementing problembased learning in a college science class. Journal of College Science Teaching. 1996; 26(1):26-30.

88-Seltzer S, Hilbert S, Maceli J, Robinson E, Schwartz D. An active approach to calculus. New Directions for Teaching and Learning. 1996 Dec; 1996(68):83-90.

89-Moore GT, Block SD, Style CB, Mitchell R. The influence of the New Pathway curriculum on Harvard medical students. Academic Medicine. 1994 Dec.

90-Saville BK. Using evidence-based teaching methods to improve education. Teaching and Learning Excellence. 2009; 14:32.

91-Stitt-Gohdes WL. Business Education Students' Preferred Learning Styles and Their Teachers' Preferred Instructional Styles: Do They Match?. Delta Pi Epsilon Journal. 2001; 43(3):137-51.

92-Farhadian F, Tootoonchi M, Changiz T, Haghani F, Oveis Gharan S. Faculty members' skills and educational needs concerning clinical teaching methods in Isfahan University of Medical Sciences. Iranian Journal of Medical Education. 2007 Jun 15; 7(1):109-18.

93-Lane IF. Change in higher education: Understanding and responding to individual and organizational resistance. Journal of Veterinary Medical Education. 2007 Apr; 34(2):85-92. 